\title{
Sustainability in the Construction Industry: A Critical Analysis Between Sustainable Development Indicators and Assessment Tools
}

\author{
Maria Teresa Barbosa ${ }^{1}$, White José dos Santos ${ }^{2}$, Marina Lucena Nogueira ${ }^{1}$, Aldo Carvalho ${ }^{1}$, Naíra Laurindo ${ }^{1}$, \\ Izabela Silva ${ }^{1} \&$ Vicente Rosse ${ }^{1}$ \\ ${ }^{1}$ Federal University of Juiz de Fora - UFJF, Juiz de Fora, Minas Gerais, Brazil \\ ${ }^{2}$ Federal University of Minas Gerais - UFMG, Belo Horizonte, Minas Gerais, Brazil \\ Correspondence: Maria Teresa Barbosa, Civil Construction Department, Engineering Faculty, Federal University \\ of Juiz de For a, José Lourenço Kelmer St., Uniersity campus, São Pedro, Juiz de Fora, Minas Gerais, Brazil. \\ E-mail: teresa.barbosa@engenharia.ufjf.br
}

Received: February 23, $2021 \quad$ Accepted: March 30, $2021 \quad$ Online Published: April 19, 2021

doi:10.5539/jms.v11n1p139 URL: https://doi.org/10.5539/jms.v11n1p139

\begin{abstract}
Nowadays, different organizations and institutions have advanced methodologies and strategies that make it possible to assess, through parameters and indicators, the sustainability of construction projects that materialize the concept of "sustainable building". The main aim of this research is to carry out a critical analysis between the Sustainable Development Indicators (SDI), released by the IBGE/Brazil, and the most used assessment tools in Brazil, namely: LEED and AQUA. Thus, with regard to the "green buildings" certified by these tools in the Brazilian territory, data collection was carried out in those organizations considering the parameters: the level of certification and the region of Brazil. The lack of synchronization between the data from the SDI and the assessment tools was found. Finally, recommendations are presented that aim to reduce the inconsistencies found in the assessment tools.
\end{abstract}

Keywords: sustainable development, green building, indicators

\section{Introduction}

The many world conferences that have taken place in recent decades have generated incentives in favor of sustainable development, proposing, in summary, to harmonize the natural and built environments indicators, the social indicators and the economic indicators of humanity, including the quality of life of individuals and communities (Haapio, 2008; Braulio-Gonzalo \& Bovea, 2020; Lazar \& Chithra, 2020; Paz et al., 2021).

In this context, the Brazilian Institute of Geography and Statistics (IBGE, 2020) makes available and periodically updates the 62 (sixty-two) "Sustainable Development Indicators in Brazil" (SDI), in accordance with the Commission on Sustainable Development of the United Nations, which are organized in four dimensions, namely: Environmental, which refers, briefly, to natural resources, correlating the objectives of preservation and conservation of the environment; Social, which illustrates, in a more comprehensive way, the living conditions of the population; Economic, which describes the macroeconomic and financial development of the country; and Institutional, which addresses the capacity and effort expended by governments and society to implement the changes required for an effective practice of sustainable development.

Correlating these facts previously described with the construction industry, Dixit et al. (2013), Graffarianhoseini and Tookey (2017) and Giannetti et al. (2018) mention the significant contribution of the sector to the implementation of the fundamental principles that govern sustainable development, since it is a branch of activity that consumes, on a large scale, natural and energy resources, contributing considerably to the global environmental, social and economic impacts.

Taking all this into account, the professionals and users involved in the construction process have incorporated the regulations that allow the implementation of "green building", moreover, many assessment tools have been developed in several countries, which differ, basically, with respect to the performance indicators adopted, such as, for example, environmental (energy and water consumption, $\mathrm{CO}_{2}$ emissions, environmental performance), economic (costs over the life cycle, durability) and social (thermal and acoustic comfort, air quality) (Ferreira \& Pinheiro, 2014; Kang et al., 2016; Graffarianhoseini \& Tookey, 2017; Barbosa \& Almeida, 2017; Lopez et al., 
2019).

Barbosa and Almeida (2016); Lazar and Chithra (2020) mention that, among the certification systems applicable to the building industry, the BREEAM (Building Research Establishment Environmental Assessment Method) was the pioneer, followed by LEED (Leadership in Energy and Environmental Design) and GBTool (Global Building Tool) organized by the iiSBE (International Initiative for Sustainable Built Environment), which later, due to economic and cultural, changed its name to SBTool (Sustainable Building Tool). As of 2005, the system HQE (Haute Qualité Environnementale dês Bâtiments) emerged, with its structure subdivided into: The Building Management System (BMG) and the Environmental Quality of the Building (EQB), as well as many others of lesser repercussion (specific to a country or a region), which meet specific regulations, and which have been and are being developed.

According to Haapio (2008), Mateus and Bragança (2011) and Alves et al. (2014) the performance indicators (qualitative and quantitative) adopted in the assessment tools usually assign scores considering the level of commitment to the requirements established for the accomplishment of a "sustainable building". The requirements are related to the construction, climatic and environmental aspects, considering the building and the context in which it is inserted, that is, its relationship with the city and the global environment.

In Brazil, there are several types of assessment tools that measure the sustainability criteria of a building, some of them more specific; however, there is a greater demand for LEED/Brazil and AQUA. According to the U.S. Green Building Council (GBC, 2020), in 2013, the tool LEED (Leadership in Energy and Environmental Design) allowed Brazil to occupy the first position in Latin America and the third in the world in number of certified buildings, behind only the United States and China, respectively. The tool AQUA, adapted from the HQE (Haute Qualité Environnementale des Bâtiments), has a less expressive application, around 14.5\%, while LEED corresponds to $85.5 \%$ of the total certified projects (VANZOLINI, 2020).

In this context, the highligth of this research is to carry out an analysis of the inconsistencies between the certification systems usually employed in Brazil, namely: LEED/Brazil and AQUA, considering the country's regional divergences, and the SDI released by IBGE. And, finally, to propose recommendations that minimize the discrepancies that have been detected, since it is possible that, in the future, a building that today qualifies as being of high quality can be considered a low-quality construction.

\section{Methodology}

Analysis of indicators of the Brazilian data provided by the IBGE, it used the tool "Sustainability Panel", enabling the separate presentation of the dimensions: environmental, social, economic and institutional, included in the Sustainable Development Index, according with procedure described by to Barbosa and Almeida (2017).

The Sustainability Panel tool is an electronic tool that displays separately the status concerning to the dimensions of Sustainable Development Index (SDI), and its main purpose is to measure the "supply" and the "fluidity" of each dimension allowing a counterweight of the dimensions in favor of the sustainability (Krama, 2008; Barbosa \& Almeida, 2017). The procedure consists in, briefly, the Excel spreadsheet, following a pre-established format with lines and columns, after than determine the reference value for each parameter seeking a leveling between them, since the panel evaluates the indicators through the data comparison.

Through this exhibition, for each dimension, an assessment of the country's profile is made. It should be noted that the construction of the database is simple, carried out through the "entry" of information through an Excel spreadsheet (Microsoft Excel program), following the format of rows and columns.

\section{Results and Discussion}

\subsection{Synthesis of Sustainable Development in Brazil}

Brazil is the fifth largest country in the world, with $8,515,767 \mathrm{~km}^{2}$, subdivided into five regions, namely: North, Northeast, Southeast, South and Midwest, see Figure 1, a country where 5,570 cities and 27 states are located and where a population of around 211 million is estimated, thus presenting a demographic density of approximately 24.8 inhabitants $/ \mathrm{km}^{2}$ (IBGE, 2020). 


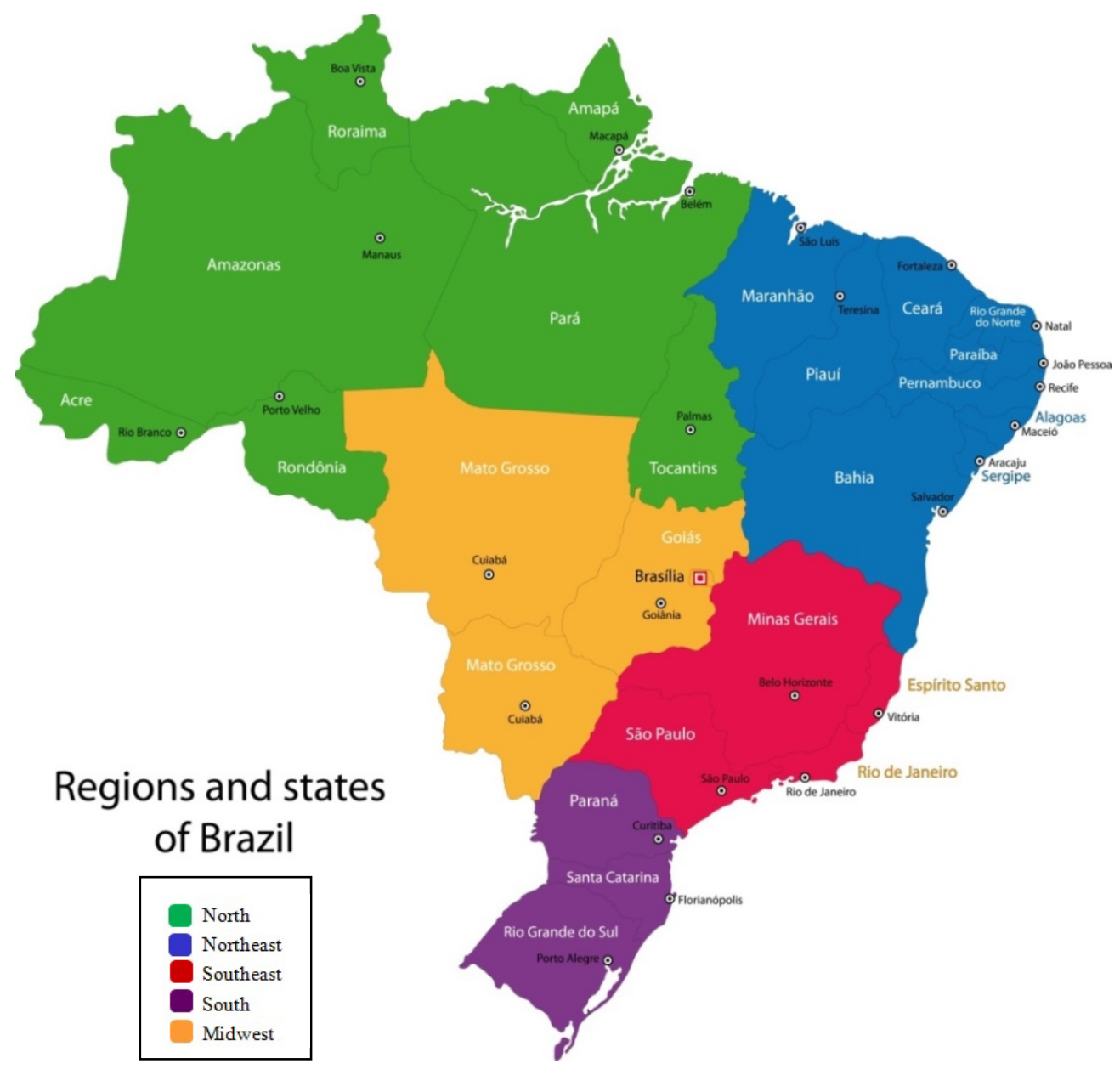

Figure 1. Political regions and Brazilian states

It is important to add that there are, in Brazil, four different time zones, as well as different climatic regions (equatorial climate, tropical climate, temperate climate, subtropical climate and semi-arid climate), which must be taken into account in the different construction practices. In this context, the global interest in sustainable development in the construction industry in Brazil is promising. The country is divided into 8 bioclimatic zones according to NBR 15220 (ABNT, 2008), in which limit parameters for major Brazilian cities were studied and recorded in this standard, namely: maximum daily temperatures, thermal amplitude, wet bulb temperature, solar radiation and cloudiness. This Brazilian bioclimatic zoning also includes a set of recommendations and constructive strategies aimed at single-family homes of social interest, in order to make them more livable and sustainable.

Therefore, the results obtained, adopting the years 2009 and 2019 as a reference, as well as a total reference equal to $100 \%$ for each of the four dimensions that make up sustainable development in the five regions of Brazil (IBGE, 2020), see Figure 2. 


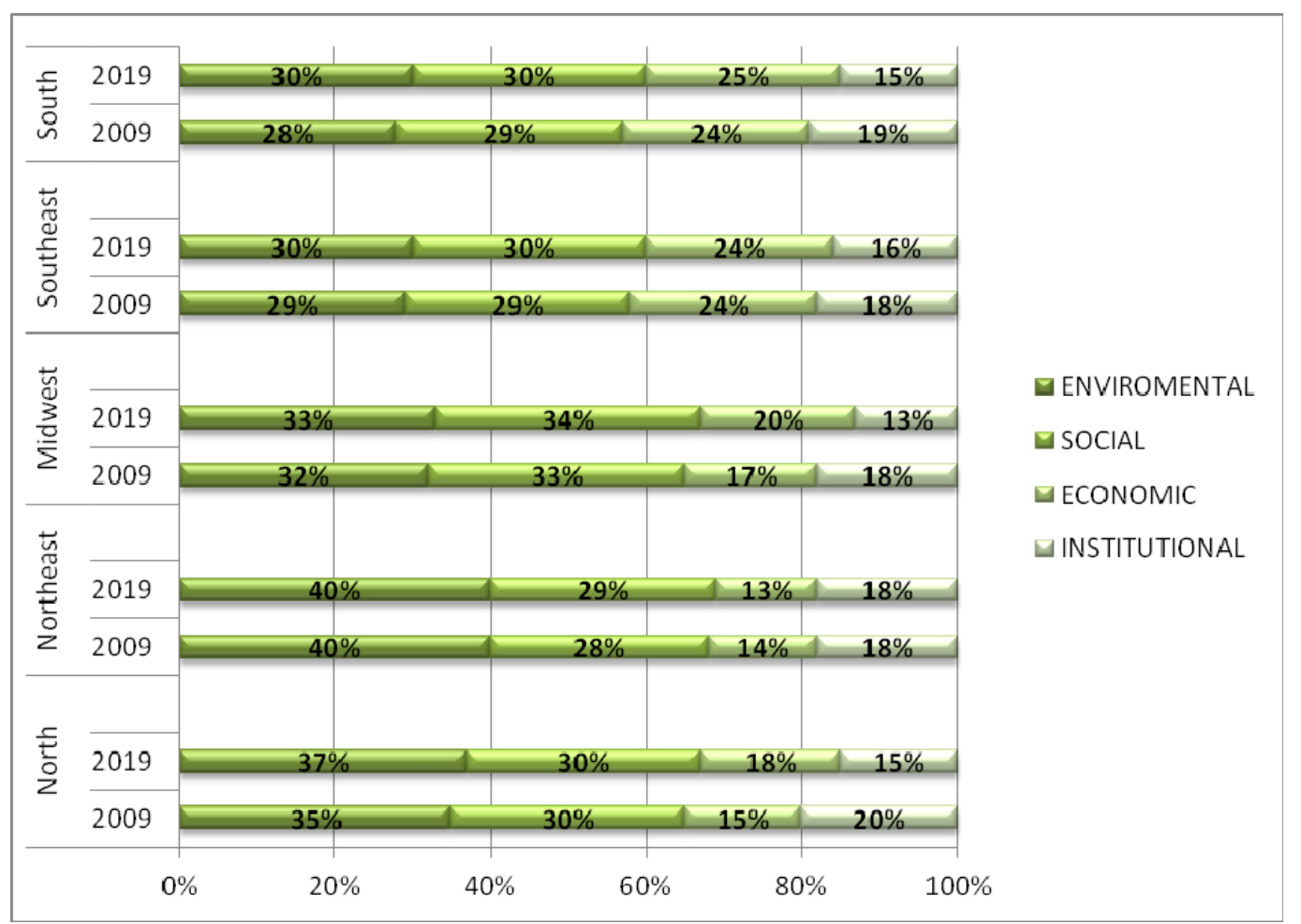

Figure 2. Sustainable development in Brazil obtained through data released by IBGE

In Figure 2, is observed that there is a greater uniformity in the distribution of actions in favor of the factors that govern the environmental dimension in Brazilian territory, with a reasonable percentage, followed by the social dimension. However, the economic and institutional dimensions are out of alignment, especially in the North and Northeast regions of the country. Feroni and Glavão (2020) mentioned the imbalance between the SDI after 2015 and remarked the need restructure public policies in search of harmony between the dimensions.

In a recent reserach presented by Paz et al. (2021), carried out in about $15 \%$ of the municipalities located in the Brazilian northeast, it was found that the environmental impacts and social inequality (see Figure 2) are increasing because there is a disorganized economic growth in Brazil. The research used of the multi-criteria method and proposed a structuring of investments in favor to the country sustainable development.

As such, contributions to Brazilian construction industry and to the consolidation of the "green building" policy are very important, especially if all regional differences are taken into account.

\subsection{Analysis of the Indicators Included in the Assessment Tool}

The tools are differentiated by the building certification process, since the tool LEED requires the fulfillment of prerequisites and sustainable credits that are linked to the project, which cover eight categories, namely: Innovation and design, Location and transportation, Sustainable implementation, Rational use of water, Energy and atmosphere, Materials and resources, Internal environmental quality and Social practices (GBC, 2020). The tool AQUA, in turn, performs a verification of the high environmental quality of the building through independent audits, providing certification to the buildings, which must have full control of the project in its phases of program, design, realization and operation. Therefore, it is necessary to implement a management system in the building, so that the performance criteria of "Environmental quality of the building" are met (VANZOLINI, 2020).

It is worth clarifying that the biggest deficiency of the tool LEED/Brazil is the possibility of certifying a construction as being of high quality even if it has been rejected on some item or does not meet some of the normative requirements, by suppressing items. The tool AQUA stands out for its low percentage in the selection of materials (below 10\%), which is responsible for the cost of a construction and also for the impact on the biodiversity of the planet (environmental and economic) (Barbosa \& Almeida, 2016, 2017).

As mentioned, in Brazil, there is a greater demand for the assessment tools: LEED/Brazil and AQUA. In this sense, it was carried out the identification of the buildings that have been certified and registered in the national territory, until the first half of 2019, including their distribution among the Brazilian macro-regions, as shown in 
Tables 1 and 2. It should be noted that the data collection consisted of a consultation with the certification institutions, which are available on the referred sites (GBC, 2020; VANZOLINI, 2020).

Table 1. Overview of LEED tool in Brazil

\begin{tabular}{llll}
\hline Region & Characteristic & Total \\
\cline { 2 - 3 } & Certified & Registered & \\
\hline North & 6 & 32 & 38 \\
Northeast & 32 & 110 & 142 \\
Midwest & 19 & 61 & 80 \\
Southeast & 441 & 1071 & 1512 \\
South & 74 & 182 & 256 \\
$\sum$ & $\mathbf{5 7 2}$ & $\mathbf{1 4 5 6}$ & $\mathbf{2 0 2 8}$ \\
\hline
\end{tabular}

Table 2. Overview of AQUA tool in Brazil

\begin{tabular}{llll}
\hline \multirow{2}{*}{ Region } & Characteristic & Total \\
\cline { 2 - 3 } & Construction & Operation & \\
\hline Norte & 2 & 0 & 2 \\
Northeast & 19 & 5 & 24 \\
Midwest & 12 & 4 & 16 \\
Southeast & 246 & 29 & 275 \\
South & 18 & 8 & 26 \\
$\sum$ & $\mathbf{2 9 7}$ & $\mathbf{4 6}$ & $\mathbf{3 4 3}$ \\
\hline
\end{tabular}

Regarding the tool LEED/Brazil, it is observed that the process consists of two stages, namely: certified, that is, the buildings that already have the "green building" seal on one of the levels: platinum, gold, silver and bronze; or registered, which consists of those that were approved in the design phase, but are awaiting certification after execution, with these two stages representing $28.21 \%$ and $71.79 \%$ of the buildings that used this type of tool, respectively.

The tool AQUA (see Table 2), in turn, is stratified according to the stage of the project: construction or operation, which have values of $86.58 \%$ and $13.42 \%$, respectively, strengthening the idea that, regardless of the type of tool to be used, the request in Brazilian construction industry occurs frequently in the design phase, often neglecting the need for greater control in the other stages of the construction process.

It should be noted that the tool LEED/Brazil allows the certification of a building as being of high quality (platinum), even if it has been rejected in some indicator, due to the possibility of suppressing items. On the other hand, the tool AQUA is characterized by the cost of a construction and its impact on the biodiversity of the planet (environmental and economic), that is, indicators such as social indicators are neglected, compromising a more careful analysis of the type of "seal" validated for the building.

\subsection{Sustainability Dimensions Employed in Assessment Tools}

In the case of Brazil, there is the Brazilian Council for Sustainable Construction (CBCS, 2020), as well as several research centers and agencies involved in the strengthening of green buildings, which seek to implement guidelines that meet the basic principles of sustainable development in the construction industry for the current century. However, there is no specific assessment tool for the country, normally, adaptations of international tools are made, which do not adequately take into account the divergences in the Brazilian territory. An illustration of this, for example, is the energy demand of buildings, which is sensitive to climatic parameters, such as: air temperature, solar gain or precipitation; its behavior is complex in buildings with different interests and requirements, because "building performance" has different indicators (environmental, social and economic).

Figure 3 illustrates the percentages of the dimensions included in the certification procedures mentioned above and those obtained from the IBGE database, making it evident the inequality between the dimensions that make up sustainable development, especially if national differences are taken into account. In this context, it is evident the need to adapt Brazilian requirements and characteristics considering the different regions of Brazil.

Considering the regional differences of the Brazilian territory — associated with public policies that, in this case, include financial and technical incentives for sustainable development-socioeconomic inequalities are 
important indicators of the need to strengthen sustainable construction. According to Costa et al. (2015), the assessment and certification tools used in the construction industry generally follow, sequentially, 4 (four) basic principles: the quantification of the building's performance at the level of each indicator; standardization of parameters; the collection of data related to the parameters; and the scores, which result in an overall assessment of the building.

The list of parameters applicable to the assessment tools is limited to the purpose of the certification and is associated with good professionals, including here the interpretation of the data and the integrity of the certification, evidencing the need for a balance between the different dimensions of sustainable development in order to improve the reliability of the tools.

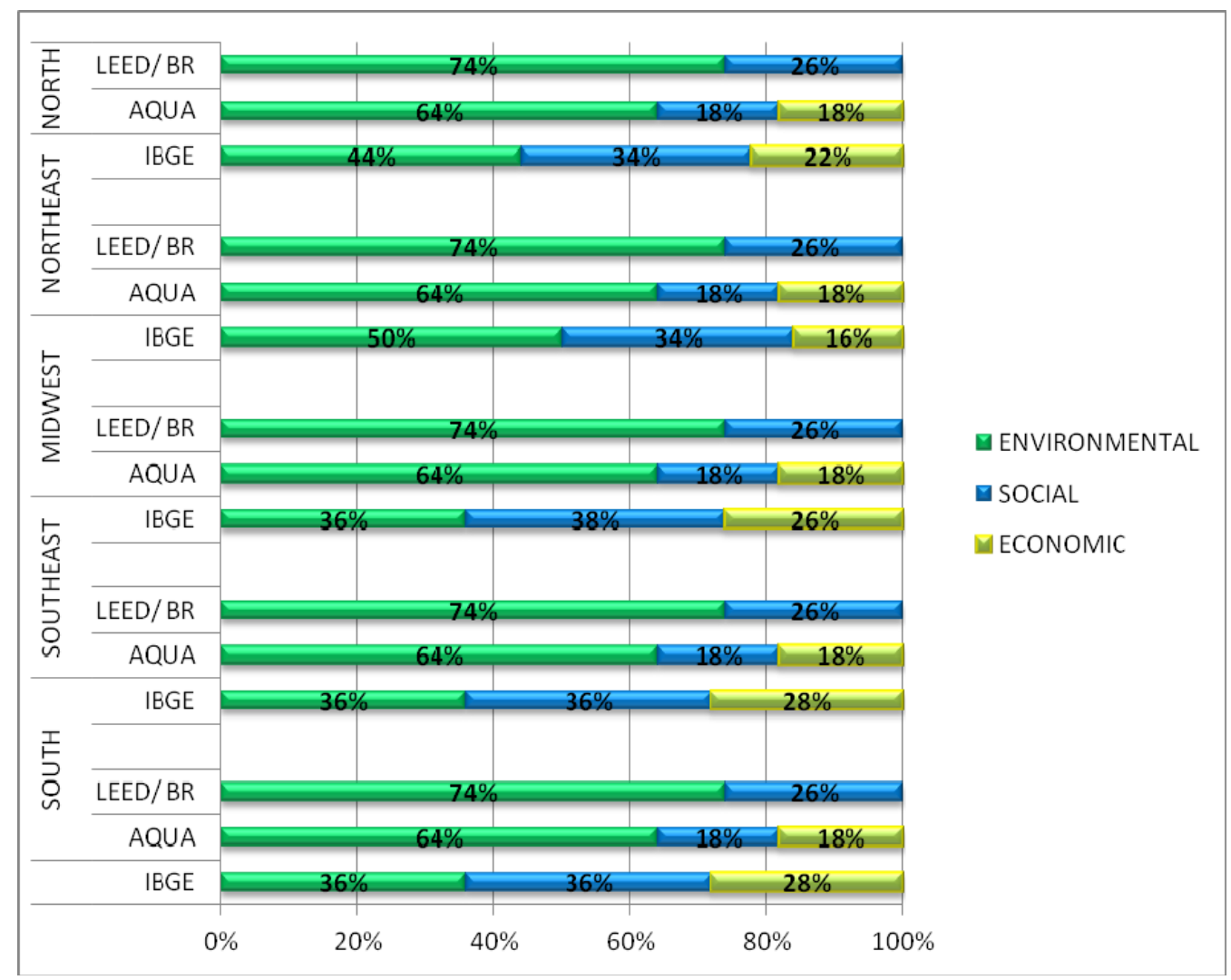

Figure 3. Weights of the dimensions included in the assessment tool: LEED/Brazil; AQUA and those obtained through IBGE data

However, in Brazil, the lack of correlation between construction and operating costs, as well as the multidisciplinary nature of those involved in the construction process, arise as difficulties for the construction industry, which generates a significant heterogeneity of products and services. Regional divergences should also be considered, which result in the specification of different materials and construction types suitable for each climatic zone and ecosystem, among others.

In this context, Mateus and Bragança (2011); Barbosa and Almeida (2017); Lazar and Chithra (2020) mention that countries that have climatic and cultural conditions various, such as Brazil, need adjustments in the assessment tools, local and/or regional. Therefore, considering that the type of tool and its applicability can be influenced by many factors, it is recommended:

i) The adequacy of the assessment tools based on a list of parameters considering the most relevant impacts of the construction and, at the same time, the regional differences in the country;

ii) Standardize a balance between all the different dimensions of sustainable development: environmental, social and economic;

iii) Enable an update of the assessment tools, seeking to minimize errors that may arise, and which are 
criticized in many surveys, such as, for example, qualitative indicators that are difficult to validate (i.e. aesthetics and technical innovation, among others);

iv) Improve reliability through the use of accepted LCA methods, that is, the construction process as a closed loop.

\section{Conclusions}

The study shows a deficiency in the consolidation of policies for the implementation of "sustainable construction" considering the extension of the Brazilian territory. On the other hand, it is clear that, among the transformations that can be implemented in the sector, the decisions in the planning and project (design) stages stand out, where environmental aspects, the surroundings and the management of resources are considered, mainly when specifying the materials, as well as those applicable to the other stages of the construction process.

It is also worth mentioning the different organizations and institutions that have developed methodologies that are based on sustainability parameters and indicators, making the concept of "sustainable construction" subjective, and the situation in Brazil is no different, despite the efforts made, the existing methodologies are sometimes considered adaptations of the international ones and neglect the divergences of the Brazilian territory.

And, finally, there are many researches about it but the weight attributed to each dimension and category in the assessment tools forget the priorities of the local context for the countries with great cultural and climatic divergences. Briefly, the categories of the assessment tools include: Site, Energy, Water, Materials, Pollution, Waste, Indoor Air Quality, and Cost. The fulfillment of each level must be carried out by highly qualified profissional in order to minimize errors. Thus, it is necessary to formulate a list of parameters considering the most relevant impacts for each region, as well as establishing the balance between the dimensions and the LCA methods.

\section{Acknowledgments}

The authors wish to thank the National Council for Scientific and Technological Development (CNPq), Coordination of Superior Level Staff Improvement (CAPES), Federal University of Juiz de Fora (UFJF) and Federal University of Minas Gerais (UFMG) for their financial support.

\section{References}

Alves, L., Melhado, S., \& Vittorino, F. (2014). Selection of building technology based on sustainability requirements-Brazilian context. Architectural Engineering and Design Management, 1, 1-15. https://doi.org/10.1080/17452007.2014.942249

Barbosa, M. T., \& Almeida, M. M. (2016). Construção sustentável: Contributo as ferramentas de avaliação. Curitiba: CRV.

Barbosa, M. T., \& Almeida, M. M. (2017). Developing the methodology for determining the relative weight of dimensions employed in sustainable building assessment tools for Brazil. Ecological Indicators, 73, 46-51, https://doi.org/10.1016/j.ecolind.2016.09.017

Braulio-Gonzalo, M., \& Bovea, M. (2020). Relationship between green public procurement criteria and sustainability assessment tools applied to office buildings. Environmental Impact Assessment Review, 81, https://doi.org/10.1016/j.eiar.2019.106310

Brazilian Association of Technical Norms (ABNT). (2008). Thermal performance in buildings Part 3: Brazilian bioclimatic zones and building guidelines for low-cost houses. Rio de Janeiro.

Conselho Brasileiro de Construção Sustentável (CBCS). (2015). Aspectos da construção sustentável no Brasil e promoção de políticas públicas. Retrieved from https://www.cbcs.org.br

Costa, M. C., Almeida, M., Cunha, R. D. A., \& César, S. F. (2015). Estudo comparativo entre as normas ISO 21931, NBR 15575 e os requisitos das Certificações AQUA e LEED. In Proceedings of EURO ELECS Connecting people and ideas. Guimarães.

Dixit, M., Culp, C. H., \& Fernández-Solis, E. J. L. (2013). System boundary for embodied energy in buildings: A conceptual model for definition. Renewable and Sustainable Energy Reviews, 21, 153-164. https://doi.org/10.1016/j.rser.2012.12.037

Feroni, R. D. C., \& Galvão, E. S. (2020). Sustainable development indicators assessment for the city of Anchieta-ES Brazil at different times of the local economy. International Journal of Sustainable Development \& World Ecology, 27(6), 524-533. https://doi.org/10.1080/13504509.2020.1738585 
Ferreira, J., \& Pinheiro, M. (2014). Portuguese sustainable construction assessment tolls benchmarked with BREEAM and LEED: An energy analysis. Energ Buildings, 69, 451-463. https://doi.org/10.1016/j.enbuild.2013.11.039

Giannetti, B., Demétrio, J. C., Agostinho, F., Almeida, C. M., \& Liu, G. (2018). Towards more sustainable social housing projects: Recognizing the importance of using local resources. Building and Environment, 127, 187-203. https://doi.org/10.1016/j.buildenv.2017.10.033

Graffarianhoseini, A., \& Tookey, J. (2017). A critical comparison of green building rating systems. Building and Environment, 123, 243-260. https://doi.org/10.1016/j.buildenv.2017.07.007

Green Building Council (GBC Brasil) - Empreendimentos LEED. (2020). Retrieved January 20, 2020, from https:/www.gbcbrasil.org.br/certificacao/certificacao-leed/empreendimentos/

Haapio, A., \& Viitaniemi, P. (2008). A critical review of building environmental assessment tools. Environmental Impact Assessment Review, 28, 469-482. https://doi.org/10.1016/j.eiar.2008.01.002

Instituto Brasileiro de Geografia e Estatística (IBGE). (2019). Indicadores do desenvolvimento sustentável. Retrieved November 20, 2019, from http://www.ibge.gov.br

Kang, H., Lee, Y., \& Kim, S. (2016). Sustainable building assessment tool for project decision makers and its development process. Environmental Impact Assessment Review, 58, 34-47. https://doi.org/10.1016/j.eiar.2016.02.003

Krama, M. (2008). Analysis of sustainable development indicators in Brazil with sustainable painel tool (p. 169). Paraná Catholic University (master's thesis). Brazil.

Lazar, N., \& Chithra, K. (2020). A comprehensive literature review on development of Building Sustainability Assessment Systems. Journal of Building Engineering, 32, 101450. https://doi.org/10.1016/j.jobe.2020.101450

López, C. D., Carpio, M., Martín-Morales, M., \& Zamorano, M. (2019). A comparative analysis of sustainable building assessment methods. Sustainable Cities and Society, 49, 101611. https://doi.org/10.1016/j.scs.2019.101611

Mateus, R., \& Bragança, L. (2011). Sustainability assessment and rating of buildings: Developing the methodology SBToolPT-H. Building and Environment, 46(10), 1962-1971. https://doi.org/10.1016/j.buildenv.2011.04.023

Paz, T. D. S. R., Caiado, R. G. G., Quelhas, O. L. G., Gavião, L. O., \& Lima, G. B. A. (2021). Assessment of sustainable development through a multi-criteria approach: Application in brazilian municipalities. Journal of Environmental Management, 282, 111954. https://doi.org/10.1016/j.jenvman.2021.111954

Vanzolini Fundation. (2020). Technical certification: AQUA assesment tool. Retrieved January, 2020, from http://www.vanzolini.org.br/hotsite-104.asp?cod_site=104

\section{Copyrights}

Copyright for this article is retained by the author, with first publication rights granted to the journal.

This is an open-access article distributed under the terms and conditions of the Creative Commons Attribution license (http://creativecommons.org/licenses/by/4.0/). 